\title{
Clinicopathological characteristics predict lymph node metastases in ypT0-2 rectal cancer after chemoradiotherapy
}

\author{
Steven L Bosch, ${ }^{1}$ Thomas A Vermeer, ${ }^{2}$ Nicholas P West, ${ }^{3}$ Hendrik A M Swellengrebel, ${ }^{4}$ \\ Corrie A M Marijnen, ${ }^{5}$ Annemieke Cats, ${ }^{4}$ Cornelis Verhoef, ${ }^{6}$ Ineke van Lijnschoten, ${ }^{7}$ \\ Johannes H W de Wilt, ${ }^{8}$ Harm J Rutten $^{2,9}$ \& Iris D Nagtegaal ${ }^{1}$ \\ ${ }^{1}$ Department of Pathology, Radboud University Medical Centre, Nijmegen, ${ }^{2}$ Department of Surgery, Catharina Hospital \\ Eindhoven, Eindhoven, the Netherlands, ${ }^{3}$ Pathology and Tumour Biology, Leeds Institute of Cancer and Pathology, \\ St James's University Hospital, University of Leeds, Leeds, UK, ${ }^{4}$ Department of Gastroenterology and Hepatology, \\ Netherlands Cancer Institute, Amsterdam, ${ }^{5}$ Department of Radiotherapy, Leids University Medical Centre, Leiden, \\ ${ }^{6}$ Department of Surgery, Erasmus MC Cancer Institute, Rotterdam, ${ }^{7}$ Pathology and Medical Microbiology, Eindhoven, \\ ${ }^{8}$ Department of Surgery, Radboud University Medical Centre, Nijmegen, and ${ }^{9}$ Department of Surgery, Maastricht \\ University Medical Centre, Maastricht, the Netherlands
}

Date of submission 16 March 2016

Accepted for publication 4 June 2016

Published online Article Accepted 6 June 2016

Bosch S L, Vermeer T A, West N P, Swellengrebel H A M, Marijnen C A M, Cats A, Verhoef C, van Lijnschoten I, de Wilt J H W, Rutten H J \& Nagtegaal I D

(2016) Histopathology. DOI: 10.1111/his.13008

\section{Clinicopathological characteristics predict lymph node metastases in ypT0-2 rectal cancer after chemoradiotherapy}

Aims: Changes in rectal cancer treatment include increasing emphasis on organ preservation. Local excision after chemoradiotherapy (CRT) for rectal cancer with excellent clinical response reduces morbidity and mortality compared to total mesorectal excision, although residual lymph node metastases (LNM) may cause local recurrence. Our aim is to identify clinicopathological factors predicting the presence of residual LNM in rectal cancer patients with ypTO-2 tumours after neoadjuvant CRT. These risk factors may help to select patients who can be spared radical surgery without compromising oncological outcomes.

Methods and results: Rectal cancer patients with ypT0-2 tumours after CRT and radical resection from five centres treated between June 1999 and February 2012 were included. Histopathology was reviewed extensively. Clinicopathological characteristics and their association with residual LNM were investigated. Of 657 consecutive CRT-treated rectal cancer patients
210 with ypT0-2 disease were included. Residual nodal disease was found in 44 cases $(21.0 \%)$. Independent predictors of LNM were clinical nodal involvement $\left(\mathrm{cN}^{+}\right)$[odds ratio (OR): 2.79, 95\% confidence interval (CI): 1.04-7.48, $P=0.042]$, high-grade histopathology assessed in the post-CRT resection specimen (OR: 6.46, 95\% CI: 1.23-34.02, $P=0.028$ ) and residual tumour diameter $(\mathrm{RTD}) \geq 10 \mathrm{~mm}$ (OR: 2.54, 95\% CI: $1.06-6.09, P=0.036)$. An algorithm combining these factors stratified patients adequately according to LNM risk, independently of ypT category. Conclusions: Clinical nodal involvement, high-grade histopathology and RTD $\geq 10 \mathrm{~mm}$ are strong and independent predictors of residual nodal disease in rectal cancer patients with ypT0-2 tumours after CRT. Risk stratification based on these factors may help to identify patients suitable for organ preserving therapy and should be validated in appropriately selected populations.

Keywords: chemoradiotherapy, local excision, lymph node metastasis, rectal cancer, ypT 


\section{Introduction}

For locally advanced rectal cancer patients, neoadjuvant chemoradiotherapy (CRT) consisting of a long course of radiotherapy and concurrent chemotherapy followed by total mesorectal excision (TME) is the standard of care. In $8-24 \%$ of patients, neoadjuvant CRT results in a pathologically complete response (pCR). These patients have been reported to have an excellent prognosis, with a 5-year local recurrence rate of $0-2.8$ and $83.3-96.9 \%$ 5-year disease-free survival. ${ }^{1-3}$

Radical resection may therefore be superfluous in selected patients with a good clinical response, and postoperative morbidity and mortality associated with $\mathrm{TME}^{4,5}$ could be avoided. Indeed, local recurrence rates as low as $2.8 \%$ and $4.7 \%$ have been reported after a wait-and-see policy for selected patients with a clinical complete response after CRT. ${ }^{6,7}$ Nevertheless, several other studies showed worse outcomes (local failure rates of $23-60 \%){ }^{8-10}$ Critics of wait-and-see point out that criteria for clinical complete response cited in the literature are not consistent and the evidence is based on highly selected patient groups. ${ }^{11}$

A full-thickness local excision of the residual tumour or scar area is an attractive alternative to wait-and-see, as it removes possible tumour remnants in the bowel wall. It also provides additional information on tumour response and can be used to identify histopathological risk factors for locally recurrent disease. Especially for early tumours in the distal part of the rectum, this strategy has been used successfully in several small international studies. ${ }^{12}$ However, identification of patients who are most likely to benefit from an organ-preserving procedure remains difficult. A validated set of histopathological risk factors could help to stratify patients according to local recurrence risk. Unfortunately, studies on local excision after CRT are relatively scarce and often lack sufficient numbers of patients to perform a risk stratification based on histopathological factors.

An alternative approach is to investigate tumour characteristics associated with residual lymph node metastases (LNM) in the mesorectal fat of CRT-treated radical TME specimens. Residual LNM are a potential source of recurrent disease after local excision and predictors of LNM in radical resection specimens are therefore likely to overlap with predictors of local recurrence after local excision. ${ }^{13,14}$ In addition, patients with ypTO-2 rectal cancers after CRT may be cured with a full-thickness local excision in the absence of LNM. We therefore investigated possible predictors of LNM in this group of patients in a multicentre study with a central review of histopathology.

\section{Materials and methods}

PATIENTS AND STUDY DESIGN

This report describes a pooled analysis of consecutive rectal cancer patients from five independent centres with ypT0-2 tumours who received neoadjuvant CRT followed by TME surgery between June 1999 and February 2012. Patients considered for CRT either had evidence of locally advanced disease on preoperative magnetic resonance imaging (MRI) (defined as a cT4 tumour, a cT3 tumour with threatened mesorectal fascia, a cT3 tumour less than $5 \mathrm{~cm}$ from the anal verge and/or clinical N2 disease), or were otherwise expected to benefit from CRT during a multidisciplinary team meeting (e.g. attempt to preserve the sphincter in case of a very low T2 tumour). Patients received an external beam long course of radiotherapy consisting of 45-50 Gy in 25-28 fractions of 1.8-2.0 Gy and concomitant fluoropyrimidine-based chemotherapy (with or without oxaliplatin). The clinical target volume included the primary tumour and the mesorectum with vascular supply, containing the perirectal, presacral and internal iliac nodes. For this purely restrospective study ethics approval and informed consent were not required.

\section{H I S T O P A T H O L O G Y}

Routine histopathological evaluation of the resection specimens was performed in the laboratories of the participating hospitals according to international guidelines. For the study, haematoxylin and eosin (H\&E)-stained glass slides or high-resolution digitally scanned slides as well as histopathology reports were retrieved and reviewed centrally by a single investigator (S.L.B.). Difficulties and discrepancies with the original histopathology report were resolved by consulting an expert gastrointestinal pathologist (I.D.N.).

Cases were excluded if a tumour was determined to be >ypT2 at review or the histopathological slides (glass or digital) were unavailable.

The pathological tumour category (урT) and pathological nodal category (ypN) were evaluated according to the TNM classification of malignant tumours, 5th edition, ${ }^{15}$ classifying mesorectal tumour deposits of $\geq 3 \mathrm{~mm}$ without evidence of residual lymph node tissue as positive lymph nodes regardless of their contour. Lymph nodes with fibrosis or acellular mucin lakes, but without viable tumour cells, were considered to be negative for tumour.

In addition to ypT category the evaluated tumourrelated characteristics included residual tumour 
diameter (RTD), histopathological type and differentiation grade, tumour regression grade (TRG), extent of tumour necrosis and presence of intramural venous and lymphatic invasion, perineural growth, budding, intramural acellular mucinous lakes, calcifications and peritumoural inflammatory infiltrate.

RTD was defined to be the largest distance between viable tumour cells in the mucosa, submucosa or muscularis propria. In the case of tumour regression with fibrosis and scattered residual tumour cells and glands, this was the largest distance between individual tumour cells in the slide. In case tumour cells were present in two slides, RTD was estimated to be at least $4 \mathrm{~mm}$, as a block of paraffin-embedded tissue was estimated to be $4 \mathrm{~mm}$ thick. This was at least $8 \mathrm{~mm}$ in the case of tumour in three slides, etc. However, due to the retrospective nature of the study it was not possible in every case to reproduce reliably the position of the various tissue blocks and associated slides relative to each other.

Histopathological type and differentiation grade of the tumour were assessed in the post-CRT resection specimen and defined according to WHO 2010 criteria. $^{16}$ For analytical purposes the cases were categorized subsequently as having high-grade histopathology (including poorly differentiated adenocarcinoma, undifferentiated carcinoma and signet ring cell carcinoma) versus other histopathology (including low-grade adenocarcinoma, mucinous carcinoma and pathological complete response).

For TRG, a four-tier grading scale adjusted from Dworak et al.'s system ${ }^{17}$ was used. Grades are defined as follows: grade 1 (no significant response) no fibrosis or significant fibrosis outgrown by cancer; grade 2 (partial response) residual cancer outgrown by fibrosis; grade 3 (near-complete response) scattered single tumour cells or small groups of tumour cells; and grade 4 (pathological complete response) no viable tumour cells.

Lymphatic invasion was defined as tumour cells in a space covered with endothelial cells in the absence of erythrocytes. ${ }^{18}$ Venous invasion was diagnosed in case of tumour within a smooth muscle-lined space or in an endothelial-lined space with additional fibrin clots, erythrocytes or both, without erythrocyte extravasation into the surrounding tissue. ${ }^{18,19}$ Budding was defined as presence of at least five foci of up to five tumour cells in a microscopic field using a $\times 20$ objective and evaluated in the area where such foci are most dense, as described by Ueno et al. ${ }^{20}$ Grade of tumour necrosis was evaluated according to Pollheimer et al. ${ }^{21}$ Acellular mucinous lakes were determined to be present or absent in the specimen regardless of tumour cells in the surrounding tissue.
Peritumoural inflammatory infiltrate was determined to be conspicuous or non-conspicuous, as described originally in the Jass and Morson classification. ${ }^{22}$

\section{STATISTICAL ANALYSIS}

SPSS version 20 was used to perform the analyses. For RTD, a receiver operating characteristic curve (ROC) was created to estimate the cut-off value with optimal sensitivity and specificity for predicting presence of LNM. The Mann-Whitney U-test or independentsamples Kruskal-Wallis test was used for non-parametric continuous variables. Categorical variables were analysed using the $\chi^{2}$ test, Mann-Whitney $U$-test or independent-samples Kruskal-Wallis test where appropriate. Factors with a statistically significant association with LNM or a statistical trend were included subsequently in a multivariate analysis using binary logistic regression. A $P$-value of $<0.05$ was considered statistically significant, whereas a $P$-value of $<0.1$ was taken to reflect a trend towards significance.

\section{Results}

P A TIENT SELECTION

Of 657 consecutive rectal cancer patients from five centres, who received a long course of CRT and TME, $211(32.1 \%)$ were found to have ypT0-2 disease. One patient was excluded for lack of histopathological slides, resulting in 210 patients who were included in the analysis.

\section{LYMPH NODES}

The median number of examined lymph nodes per patient was 7 (range: 0-39). Residual nodal disease was found in 44 patients $(21.0 \%)$. The presence of LNM was not related to number of lymph nodes sampled in the current population (median number of examined lymph nodes: 6.5 versus 7.0, respectively, in patients with versus without residual LNM $(P=0.439)$. Of the patients without LNM, 34 showed signs of tumour regression in lymph nodes, including acellular mucin in seven cases.

\section{CLINICAL CHARACTERISTICS}

Table 1 shows clinical characteristics and their association with presence of LNM. Centre of origin, gender, clinical nodal status $(\mathrm{cN})$ and type of chemotherapy (fluoropyrimidine only versus capecitabine + oxaliplatin) were associated significantly with the presence of LNM. 
4 S L Bosch et al.

Table 1. Association of clinical characteristics with residual lymph node metastases

\begin{tabular}{|c|c|c|c|c|c|}
\hline \multirow{3}{*}{$\begin{array}{l}\text { Clinical characteristics } \\
\text { Total } N=210\end{array}$} & \multicolumn{5}{|c|}{ Univariate analysis } \\
\hline & \multicolumn{2}{|l|}{ ypNO } & \multicolumn{2}{|c|}{$\mathrm{ypN}^{+}$} & \multirow[b]{2}{*}{$P$-value* } \\
\hline & $n$ & $\%$ & $n$ & $\%$ & \\
\hline Total no. of patients & 166 & 79.0 & 44 & 21.0 & \\
\hline Age (years) $\$$ & \multicolumn{2}{|l|}{$62(55-68)$} & \multicolumn{2}{|c|}{$59.5(54.25-69.75)$} & $0.665 \dagger$ \\
\hline $\begin{array}{l}\text { Total number of } \\
\text { examined lymph } \\
\text { nodest }\end{array}$ & \multicolumn{2}{|l|}{$7(4-11)$} & \multicolumn{2}{|c|}{$6.5(5-12.75)$} & $0.439 \dagger$ \\
\hline \multicolumn{6}{|l|}{ Centre of origin } \\
\hline Centre 1 & 64 & 86.5 & 10 & 13.5 & \multirow[t]{5}{*}{0.004} \\
\hline Centre 2 & 27 & 61.4 & 17 & 38.6 & \\
\hline Centre 3 & 21 & 70.0 & 9 & 30.0 & \\
\hline Centre 4 & 6 & 75.0 & 2 & 25.0 & \\
\hline Centre 5 & 48 & 88.9 & 6 & 11.1 & \\
\hline \multicolumn{6}{|l|}{ Gender } \\
\hline Male & 125 & 83.9 & 24 & 16.1 & \multirow[t]{2}{*}{0.007} \\
\hline Female & 41 & 67.2 & 20 & 32.8 & \\
\hline \multicolumn{6}{|l|}{ cT } \\
\hline $\mathrm{cT} 2$ & 7 & 87.5 & 1 & 12.5 & \multirow[t]{4}{*}{$0.184 \dagger$} \\
\hline cT3 & 99 & 75.6 & 32 & 24.4 & \\
\hline cT4 & 60 & 85.7 & 10 & 14.3 & \\
\hline Missing & - & - & 1 & - & \\
\hline \multicolumn{6}{|l|}{$\mathrm{cN}$} \\
\hline $\mathrm{cNO}$ & 60 & 89.6 & 7 & 10.4 & \multirow[t]{3}{*}{0.018} \\
\hline $\mathrm{cN}^{+}$ & 98 & 75.4 & 32 & 24.6 & \\
\hline Missing & 8 & - & 5 & - & \\
\hline \multicolumn{6}{|l|}{ Type of chemotherapy } \\
\hline FP only§ & 121 & 75.6 & 39 & 24.4 & \multirow[t]{3}{*}{0.033} \\
\hline CAPOX & 44 & 89.8 & 5 & 10.2 & \\
\hline Missing & 1 & - & - & - & \\
\hline \multicolumn{6}{|l|}{ Distance to anal verge } \\
\hline$<5 \mathrm{~cm}$ & 92 & 82.9 & 19 & 17.1 & \multirow[t]{2}{*}{0.148} \\
\hline$\geq 5 \mathrm{~cm}$ & 74 & 74.7 & 25 & 25.3 & \\
\hline
\end{tabular}

FP, Fluoropyrimidine; CAPOX, Capecitabine + oxaliplatin; cT, Clinical primary tumour category; cN, Clinical nodal category; ypT, Pathological primary tumour category after multimodality therapy; $y \mathrm{pN}$, Pathological nodal category after multimodality therapy.

$* \chi^{2}$ test is used unless stated otherwise; $†$ Mann-Whitney $U$-test; $\ddagger$ median and interquartile range; $\S$ Capecitabine $(n=139)$ or bolus $5 \mathrm{FU}+$ leucovorin $(n=21$; centres 1 and 4$)$. 
Table 2. Association of pathological characteristics with residual lymph node metastases

\begin{tabular}{|c|c|c|c|c|c|}
\hline \multirow{3}{*}{$\begin{array}{l}\text { Histopathological } \\
\text { characteristics } \\
\text { Total } N=210\end{array}$} & \multicolumn{5}{|c|}{ Univariate analysis } \\
\hline & \multicolumn{2}{|c|}{ ypNO } & \multicolumn{2}{|c|}{$\mathrm{ypN}^{+}$} & \multirow[b]{2}{*}{$P$-value* } \\
\hline & $n$ & $\%$ & $n$ & $\%$ & \\
\hline Total no. of patients & 166 & 79.0 & 44 & 21.0 & \\
\hline \multicolumn{6}{|l|}{ урт } \\
\hline урто & 71 & 82.6 & 15 & 17.4 & 0.159 \\
\hline урT1 & 23 & 85.2 & 4 & 14.8 & $0.112+$ \\
\hline урт2 & 72 & 74.2 & 25 & 25.8 & \\
\hline \multicolumn{6}{|l|}{ RTD } \\
\hline$<10 \mathrm{~mm}$ & 137 & 84.0 & 26 & 16.0 & 0.001 \\
\hline$\geq 10 \mathrm{~mm}$ & 29 & 61.7 & 18 & 38.3 & \\
\hline \multicolumn{6}{|c|}{ Histopathological type/grade§ } \\
\hline Other & 163 & 80.7 & 39 & 19.3 & 0.003 \\
\hline High grade & 3 & 37.5 & 5 & 62.5 & \\
\hline \multicolumn{6}{|l|}{ TRG } \\
\hline $\mathrm{pCR}$ & 71 & 82.6 & 15 & 17.4 & $0.769 \dagger$ \\
\hline $\begin{array}{l}\text { Near complete } \\
\text { response }\end{array}$ & 16 & 66.7 & 8 & 33.3 & \\
\hline Partial response & 76 & 80.9 & 18 & 19.1 & \\
\hline $\begin{array}{l}\text { No significant } \\
\text { response }\end{array}$ & 3 & 50.0 & 3 & 50.0 & \\
\hline \multicolumn{6}{|c|}{ Intramural venous invasion } \\
\hline Present & 0 & - & 0 & - & NA \\
\hline Absent & 166 & 79.0 & 44 & 21.0 & \\
\hline \multicolumn{6}{|c|}{ Intramural lymphatic channel invasion } \\
\hline Present & 11 & 68.8 & 5 & 31.2 & 0.292 \\
\hline Absent & 155 & 79.9 & 39 & 20.1 & \\
\hline \multicolumn{6}{|c|}{ Intramural perineural growth } \\
\hline Present & 0 & - & 0 & - & NA \\
\hline Absent & 166 & 79.0 & 44 & 21.0 & \\
\hline \multicolumn{6}{|l|}{ Budding } \\
\hline Positive & 8 & 61.5 & 5 & 38.5 & 0.117 \\
\hline Negative & 155 & 79.9 & 39 & 20.1 & \\
\hline Missing & 3 & - & - & - & \\
\hline
\end{tabular}

Table 2. (Continued)

\begin{tabular}{|c|c|c|c|c|c|}
\hline \multirow{3}{*}{$\begin{array}{l}\text { Histopathological } \\
\text { characteristics } \\
\text { Total } N=210\end{array}$} & \multicolumn{5}{|c|}{ Univariate analysis } \\
\hline & \multicolumn{2}{|c|}{ ypNO } & \multicolumn{2}{|c|}{$\mathrm{ypN}^{+}$} & \multirow[b]{2}{*}{$P$-value* } \\
\hline & $n$ & $\%$ & $n$ & $\%$ & \\
\hline \multicolumn{6}{|l|}{ Necrosis } \\
\hline Absent & 136 & 81.0 & 32 & 19.0 & \multirow[t]{4}{*}{$0.117 i$} \\
\hline Focal $(<10 \%)$ & 17 & 81.0 & 4 & 19.0 & \\
\hline Moderate $(10-30 \%)$ & 4 & 44.4 & 5 & 55.6 & \\
\hline Extensive $(>30 \%)$ & 8 & 72.7 & 3 & 27.3 & \\
\hline
\end{tabular}

Peritumoural inflammatory infiltrate

\begin{tabular}{lrrrrr}
\hline Conspicuous & 27 & 73.0 & 10 & 27.0 & 0.317 \\
\cline { 1 - 5 } Other & 139 & 80.3 & 34 & 19.7 & \\
\cline { 1 - 5 }
\end{tabular}

Acellular mucinous lakes

\begin{tabular}{|c|c|c|c|c|c|}
\hline Present & 40 & 75.5 & 13 & 24.5 & 0.459 \\
\hline Absent & 126 & 80.3 & 31 & 19.7 & \\
\hline \multicolumn{6}{|c|}{ Calcification } \\
\hline Present & 42 & 85.7 & 7 & 14.3 & 0.190 \\
\hline Absent & 124 & 77.0 & 37 & 23.0 & \\
\hline
\end{tabular}

урT, Pathological primary tumour category after multimodality therapy; ypN, Pathological nodal category after multimodality therapy; RTD, Residual tumour diameter; TRG, Tumour regression grade; $\mathrm{PCR}$, Pathological complete response; NA, Not available.

$* \chi^{2}$ test is used unless stated otherwise; $\uparrow$ Mann-Whitney U-test; †урT0-1 versus урт2; §Other histopathology includes low-grade adenocarcinoma $(n=103)$, mucinous carcinoma $(n=13)$ and pathological complete response $(n=86)$. High grade histopathology includes poorly differentiated carcinoma $(n=6)$, and undifferentiated carcinoma $(n=2)$.

\section{HIS TOP A THOLOGICAL TUMOUR CHAR A C TERISTICS}

Changes in classification of histopathological characteristics compared with the original pathology reports were made in 18 cases after slide review $(8.6 \%)$. This included either a T-category downgrade $(n=8)$, T-category upgrade $(n=6)$, N-category downgrade $(n=1)$ or N-category upgrade $(n=3)$. Tumour type was not changed. Other factors investigated in this study (e.g. tumour differentiation grade, lymphatic invasion, TRG, budding, etc.) were not described consistently in the original reports and were therefore scored primarily at the time of slide review. 
Table 3. Multivariate analysis

\begin{tabular}{|c|c|c|}
\hline & Odds ratio $(95 \% \mathrm{Cl})$ & $P$-value \\
\hline \multicolumn{3}{|c|}{ Centre of origin } \\
\hline Centre 1 & 1.00 & \multirow[t]{5}{*}{0.426} \\
\hline Centre 2 & $1.42(0.37-5.42)$ & \\
\hline Centre 3 & $1.32(0.32-5.46)$ & \\
\hline Centre 4 & $0.0(0.0-\infty)$ & \\
\hline Centre 5 & $0.48(0.11-2.07)$ & \\
\hline \multicolumn{3}{|l|}{ Gender } \\
\hline Male & 1.00 & \multirow[t]{2}{*}{0.110} \\
\hline Female & $1.98(0.86-4.59)$ & \\
\hline \multicolumn{3}{|l|}{$\mathrm{cN}$} \\
\hline cNO & 1.00 & \multirow[t]{2}{*}{$0.042^{*}$} \\
\hline $\mathrm{cN}^{+}$ & $2.79(1.04-7.48)$ & \\
\hline \multicolumn{3}{|c|}{ Type of chemotherapy } \\
\hline FP only & 1.00 & \multirow[t]{2}{*}{0.298} \\
\hline CAPOX & $0.45(0.10-2.01)$ & \\
\hline \multicolumn{3}{|l|}{ RTD } \\
\hline$<10 \mathrm{~mm}$ & 1.00 & \multirow[t]{2}{*}{$0.036^{*}$} \\
\hline$\geq 10 \mathrm{~mm}$ & $2.54(1.06-6.09)$ & \\
\hline \multicolumn{3}{|l|}{ Histopathology } \\
\hline Other & 1.00 & \multirow[t]{2}{*}{$0.028^{*}$} \\
\hline High grade & $6.46(1.23-34.02)$ & \\
\hline
\end{tabular}

cN, Clinical nodal category; RTD, Residual tumour diameter; FP, Fluoropyrimidine; CAPOX, Capecitabine + oxaliplatin; $\mathrm{Cl}$, Confidence interval.

*Statistically significant $(P<0.05)$.
Table 2 shows the investigated histopathological characteristics and the associated LNM rate. The ypT category did not predict residual nodal disease significantly (LNM rate: $17.4 \%, 14.8 \%$ and $25.8 \%$ for ypT0, ypT1 and ypT2, respectively; $P=0.159$; and LNM rate $16.8 \%$ versus $25.8 \%$ for ypT0- 1 versus ypT2, respectively; $P=0.112$ ). RTD had a strong association with presence of LNM. Initial analysis of histopathological characteristics revealed that mean RTD was significantly higher in the $\mathrm{ypN}^{+}$compared to the ypNO group (11.2 and $6.0 \mathrm{~mm}$, respectively, $P=0.022$ ). A ROC curve showed a RTD of $\geq 10 \mathrm{~mm}$ to be the optimal cutoff value to predict LNM (sensitivity $43.2 \%$; specificity $81.9 \%$; area under the curve: 0.598 ). Therefore, this value was used in the subsequent analyses which showed LNM in 16.0 versus $38.3 \%$ for RTD $<10 \mathrm{~mm}$ and $\geq 10 \mathrm{~mm}$, respectively $(P=0.001)$.

Of 24 patients with a near-complete response (TRG 3) there were three with a RTD of $\geq 10 \mathrm{~mm}$ and one of those showed residual nodal disease.

High-grade histopathology (assessed after neoadjuvant therapy) was found in eight patients, including six with poorly differentiated adenocarcinoma and two with undifferentiated carcinoma. There were no cases with signet ring cell carcinoma. The majority of patients had other histopathology $(n=202)$, including low-grade adenocarcinoma $(n=103)$, mucinous carcinoma $(n=13)$ and pathological complete response $(n=86)$. High-grade histopathology was a statistically significant predictor for the presence of LNM [LNM rate 62.5 versus $19.3 \%$ for high-grade versus other histopathology, respectively $(P=0.003)]$.

\section{ROUTINE HISTOPATHOLOGY DETAILS}

The median number of tissue blocks available for reevaluation per case was 15 (range: 5-52) and the

Table 4. Independent risk factors and lymph node metastases rate $(L N M)(n=197 \wedge)$; figures represent patients with LNM in each subgroup: \% $(n / N$ total)

\begin{tabular}{|c|c|c|c|c|c|}
\hline \multicolumn{3}{|l|}{ cNO } & \multicolumn{3}{|l|}{$\mathrm{cN}^{+}$} \\
\hline & $\begin{array}{l}\text { Other } \\
\text { histopathology }\end{array}$ & $\begin{array}{l}\text { High grade } \\
\text { histopathology }\end{array}$ & & $\begin{array}{l}\text { Other } \\
\text { histopathology }\end{array}$ & $\begin{array}{l}\text { High grade } \\
\text { histopathology }\end{array}$ \\
\hline $\mathrm{RTD}<10 \mathrm{~mm}$ & $8.0 \%(4 / 50)$ & $100.0 \%(1 / 1)$ & $\mathrm{RTD}<10 \mathrm{~mm}$ & $17.8 \%(18 / 101)^{*}$ & $25.0 \%(1 / 4) \dagger$ \\
\hline $\mathrm{RTD} \geq 10 \mathrm{~mm}$ & $6.7 \%(1 / 15)$ & $100.0 \%(1 / 1)$ & $\mathrm{RTD} \geq 10 \mathrm{~mm}$ & $47.8 \%(11 / 23)$ & $100.0 \%(2 / 2)$ \\
\hline Total & $7.7 \%(5 / 65)$ & $100.0 \%(2 / 2)$ & Total & $23.4 \%(29 / 124)$ & $50.0 \%(3 / 6)$ \\
\hline
\end{tabular}

$\mathrm{cN}$, Clinical nodal category; RTD, Residual tumour diameter; ^cases with at least one missing value $(n=13)$ were excluded; $* P=0.002$ for $\mathrm{RTD}<10 \mathrm{~mm}$ versus $\mathrm{RTD} \geq 10 \mathrm{~mm} ; \uparrow P=0.083$ for $\mathrm{RTD}<10 \mathrm{~mm}$ versus $\mathrm{RTD} \geq 10 \mathrm{~mm}$. 
Figure 1. Flowchart depicting algorithm for risk stratification. LNM, lymph node metastases; $\mathrm{cN}$, clinical nodal category.

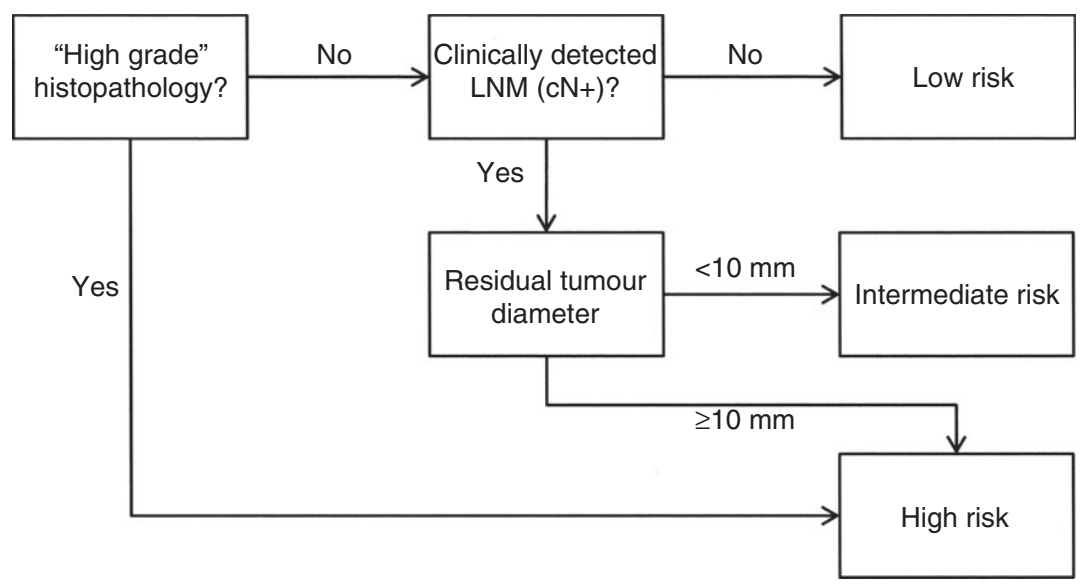

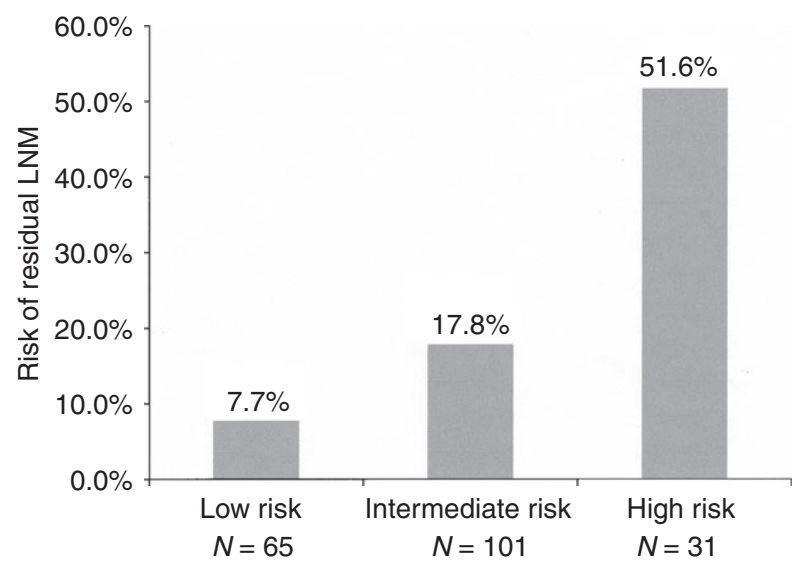

Figure 2. Risk of residual lymph node metastases (LNM) based on the flowchart algorithm* $\left(n=197^{\wedge}\right)$. ${ }^{*}$ Risk factors are: clinical nodal involvement $\left(\mathrm{cN}^{+}\right)$, residual tumour diameter $\geq 10 \mathrm{~mm}$ and high-grade histopathology (including poorly differentiated and undifferentiated carcinoma). ${ }^{\wedge}$ Cases with at least one missing value $(n=13)$ were excluded.

median number of blocks from the tumour area was six (range: 2-43). The proportion of cases in which the entire tumour area was embedded could not be determined reliably retrospectively, as this was not described consistently in the original reports. Additional tumour area blocks were embedded in 23 cases $(11.0 \%)$ that lacked residual viable tumour in the initial slides, and this included 14 patients with ypT0 $(16.3 \%)$. Three additional levels from the tumour blocks were cut in five cases $(2.4 \%)$, including two cases with ypT0 $(2.3 \%)$. Immunohistochemistry with cytokeratins was performed in 12 cases $(5.7 \%)$, including five 5 patients $(5.8 \%)$ with ypT0.

\section{MULTIVARIATE ANALYSIS}

Factors with a statistically significant association with residual nodal disease or a statistical trend were included in a multivariate analysis (Table 3). Independent predictive value was shown for clinical nodal involvement [odds ratio (OR): $2.79,95 \%$ confidence interval (CI): $1.04-7.48$ for $\mathrm{cN}^{+}$versus $\mathrm{cNO}$; $P=0.042]$, RTD $\geq 10 \mathrm{~mm}$ (OR: 2.54 , 95\% CI $1.06-$ 6.09 for $\mathrm{RTD} \geq 10$ versus $<10 \mathrm{~mm} ; P=0.036)$ and high-grade histopathology (OR: 6.46, 95\% CI: 1.2334.02 for high-grade versus other histopathology; $P=0.028)$. Centre of origin, gender and type of chemotherapy did not show an independent association with ypN category.

\section{COMBINING INDEPENDENT RISK FACTORS}

The independent risk factors identified in the multivariate analysis were combined subsequently to investigate their potential for risk stratification in the current study population (Table 4). Patients without clinically detectable LNM (cNO) and with other histopathology had the lowest LNM risk (7.7\%), whereas patients with high-grade histopathology had a high risk regardless of clinical nodal status and RTD. RTD was of additional value for stratification of patients who had both clinical nodal involvement $\left(\mathrm{cN}^{+}\right)$and other histopathology $(17.8 \%$ versus $47.8 \%$ for RTD $<10 \mathrm{~mm}$ and $\geq 10 \mathrm{~mm}$, respectively; $P=0.002$ ).

Based on these data we devised an algorithm which stratifies patients in three subgroups (low, intermediate and high risk) according to risk of residual LNM (Figure 1). LNM risk was 7.7\%, 17.8\% and $51.6 \%$ for the low, intermediate and high-risk categories, respectively $(P<0.001$; Figure 2$)$.

\section{ROLE OF YPT CATEGORY}

The ypT category did not reach statistical significance or a statistical trend in this study. In a subgroup 
analysis of patients with a ypT2 tumour $(n=88)$, the algorithm described in the previous paragraph was able to stratify patients adequately according to LNM risk $(7.7 \%, 14.7 \%$ and $50.0 \%$ for patients in the low, intermediate and high-risk categories, respectively; $P<0.001)$. For patients with a ypT0-1 tumour this was $7.7 \%, 19.4 \%$ and $66.7 \%(P=0.024)$. Patients with a pathological complete response of the primary tumour (ypT0) had residual nodal disease in $10.3 \%$ and $20.8 \%$ of cases depending on clinical nodal status $\left(\mathrm{cNO}\right.$ and $\mathrm{cN}^{+}$respectively; $P=0.231$ ).

\section{Discussion}

In this study including 210 TME specimens of consecutive rectal cancer patients with ypT0-2 tumours after CRT, we showed that clinical nodal involvement $\left(\mathrm{cN}^{+}\right)$, high-grade histopathology (i.e. poorly differentiated or undifferentiated carcinoma) and RTD of $\geq 10 \mathrm{~mm}$ are strong independent risk factors for residual LNM. We devised an algorithm based on these risk factors, which stratifies patients adequately according to risk of residual nodal disease in the current population. Moreover, we showed that the predictive value of this algorithm was independent of pathological tumour category after neoadjuvant treatment (ypT).

Clinically suspected nodal disease was the strongest independent risk factor for residual LNM at histopathological examination. Residual LNM risk in $\mathrm{cN}^{+}$patients was $24.6 \%$, which explains why clinical trials investigating feasibility of local excision after CRT generally exclude patients with clinical evidence of nodal involvement. ${ }^{23,24}$ However, LNM rate was $10.4 \%$ in the cNO group, showing that clinical imaging is relatively inaccurate for the prediction of nodal disease. $^{25,26}$

RTD was useful only in $\mathrm{cN}^{+}$patients. RTD can be regarded as a footprint of the original tumour which reflects its level of therapy resistance, similar to TRG. TRG correlates with the therapy resistance of associated LNM, with similar levels of regression in both the primary tumour and the lymph nodes. ${ }^{27}$ The predictive value of RTD is based most probably on the same principle. In the case of a local excision, the advantage of RTD over TRG is that it is based on the amount of microscopically detectable residual tumour in the specimen, whereas for TRG an estimate of the amount of tumour mass turned fibrosis is essential. ${ }^{17}$ Estimates of TRG are therefore not feasible after local excision, as an important part of the fibrotic areas are located in the mesorectal fat and therefore missing in the specimen.
High-grade histopathology was a strong and independent risk factor associated with a $62.5 \%$ risk of LNM, although it was found in relatively few cases in the current population. This result is in accordance with previous series on early colorectal cancer. ${ }^{20,28}$ Differentiation grade was determined in the CRT-treated resection specimens, as pretherapy biopsies are notoriously unreliable for grading purposes with substantial variation between grade of differentiation determined on biopsy and after definitive surgery, ${ }^{29}$ due probably to sampling error. Indeed, WHO criteria define type and grade according to the relative dominance of specific tumour components (e.g. more or less than $50 \%$ gland formation; more or less than $50 \%$ mucin production), ${ }^{16}$ and a superficial biopsy may miss a relevant component entirely. Conversely, CRT may induce significant morphological changes, including disappearance of tumour tissue with fibrosis and mucinous degeneration. ${ }^{30}$ This may change the proportion of various tumour components and may yield a different grade than would have been the case without neoadjuvant treatment. However, as both the primary tumour and LNM have been reported to undergo similar levels of regression with loss of the most susceptible tumour components, ${ }^{27}$ it may be hypothesized that the post-CRT morphology is likely to reflect the risk of residual LNM most adequately.

The relatively low number of examined lymph nodes is a limitation to this study, as a minimum of 12 nodes is generally recommended for adequate nodal staging. ${ }^{31}$ However, lymph node yield is known to decrease after chemoradiation, and the median number of seven nodes found in this study is comparable with results described in several previous reports after neoadjuvant therapy. ${ }^{32-35}$ Lymph node yield was not associated with nodal positivity in the current population. However, this may be related to a lack of statistical power to detect a correlation, as previous studies found the LNM rate to increase with the number of examined lymph nodes. ${ }^{33,34}$

Furthermore, the multicentre design of this study implies some inherent variations between centres in distribution of patient and treatment characteristics, such as gender, clinical stage and type of chemotherapy. However, the included rectal cancer patients constitute an adequate reflection of the case-mix encountered in clinical practice, and results may therefore be applicable widely. Moreover, the multivariate analysis showed the identified risk factors to be independent of centre.

However, the current results cannot be extrapolated directly to a local excision setting. For example, 
pathological tumour category may be underestimated in local excision specimens due to the often discontinuous nature of residual tumour foci after neoadjuvant CRT, as some residual tumour cells may remain undetected in the mesorectal fibrosis. Furthermore, our study is based on a relatively unfavourable population, including many patients with unfavourable clinical characteristics such as T4 tumours or clinical N2 disease, and many of them would in practice never be considered for rectal preservation. Therefore, our results are hypothesis-generating, and the identified risk factors, as well as their association with local recurrence risk, should be investigated and validated in appropriately selected populations.

In summary, this study shows that clinical nodal involvement, high-grade histopathology and RTD are strong and independent predictors for the presence of residual nodal disease in rectal cancer patients with ypT0-2 tumours after neoadjuvant CRT. An algorithm combining these risk factors to stratify patients according to low, intermediate or high LNM risk was shown to be accurate, regardless of ypT category. If validated in appropriately selected populations these factors may contribute to an effective stratification of patients according to risk of LNM and local recurrence. This may improve decision-making regarding local or radical surgery, and may help to save selected patients from undergoing an unnecessary, yet potentially harmful, TME while ensuring oncological safety.

\section{Acknowledgements}

N.P.W. is funded by the Pathological Society of Great Britain and Ireland, the Academy of Medical Sciences, the National Institute for Health Research and Yorkshire Cancer Research.

\section{Conflicts of interest}

No conflicts of interest declared.

\section{References}

1. Sauer R, Becker H, Hohenberger W et al. Preoperative versus postoperative chemoradiotherapy for rectal cancer. N. Engl. J. Med. 2004; 351; 1731-1740.

2. Maas M, Nelemans PJ, Valentini V et al. Long-term outcome in patients with a pathological complete response after chemoradiation for rectal cancer: a pooled analysis of individual patient data. Lancet Oncol. 2010; 11; 835-844.

3. de Campos-Lobato LF, Stocchi L, da Luz Moreira A et al. Pathologic complete response after neoadjuvant treatment for rectal cancer decreases distant recurrence and could eradicate local recurrence. Ann. Surg. Oncol. 2011; 18; 1590-1598.

4. Borowski DW, Bradburn DM, Mills SJ et al. Volume-outcome analysis of colorectal cancer-related outcomes. Br. J. Surg. 2010; 97; 1416-1430.

5. Paun BC, Cassie S, MacLean AR, Dixon E, Buie WD. Postoperative complications following surgery for rectal cancer. Ann. Surg. 2010; 251; 807-818.

6. Habr-Gama A, Perez RO, Nadalin W et al. Long-term results of preoperative chemoradiation for distal rectal cancer correlation between final stage and survival. J. Gastrointest. Surg. 2005; 9; 90-9; discussion 99-101.

7. Maas M, Beets-Tan RG, Lambregts DM et al. Wait-and-see policy for clinical complete responders after chemoradiation for rectal cancer. J. Clin. Oncol. 2011; 29; 4633-4640.

8. Habr-Gama A, Gama-Rodrigues J, Sao Juliao GP et al. Local recurrence after complete clinical response and watch and wait in rectal cancer after neoadjuvant chemoradiation: impact of salvage therapy on local disease control. Int. J. Radiat. Oncol. Biol. Phys. 2014; 88; 822-828.

9. Hughes R, Harrison M, Glynne-Jones R. Could a wait and see policy be justified in T3/4 rectal cancers after chemo-radiotherapy? Acta Oncol. 2010; 49; 378-381.

10. Lim L, Chao M, Shapiro J et al. Long-term outcomes of patients with localized rectal cancer treated with chemoradiation or radiotherapy alone because of medical inoperability or patient refusal. Dis. Colon Rectum 2007; 50; 2032-2039.

11. Glynne-Jones R, Hughes R. Critical appraisal of the wait and see approach in rectal cancer for clinical complete responders after chemoradiation. Br. J. Surg. 2012; 99; 897-909.

12. Borschitz T, Wachtlin D, Mohler M, Schmidberger H, Junginger T. Neoadjuvant chemoradiation and local excision for T2-3 rectal cancer. Ann. Surg. Oncol. 2008; 15; 712-720.

13. Park IJ, You YN, Skibber JM et al. Comparative analysis of lymph node metastases in patients with ypT0-2 rectal cancers after neoadjuvant chemoradiotherapy. Dis. Colon Rectum 2013; 56; $135-141$.

14. Read TE, Andujar JE, Caushaj PF et al. Neoadjuvant therapy for rectal cancer: histologic response of the primary tumor predicts nodal status. Dis. Colon Rectum 2004; 47; 825-831.

15. Sobin LH, Fleming ID. TNM, Classification of Malignant Tumors, 5th edition. Union Internationale Contre le Cancer and the American Joint Committee on Cancer. Cancer 1997; 80; 1803-1804.

16. Bosman FT, World Health Organization, International Agency for Research on Cancer. WHO classification of tumours of the digestive system. 4th edn. Lyon: International Agency for Research on Cancer, 2010.

17. Dworak O, Keilholz L, Hoffmann A. Pathological features of rectal cancer after preoperative radiochemotherapy. Int. J. Colorectal Dis. 1997; 12; 19-23.

18. Wang HS, Liang WY, Lin TC et al. Curative resection of T1 colorectal carcinoma: risk of lymph node metastasis and longterm prognosis. Dis. Colon Rectum 2005; 48; 1182-1192.

19. Tsuruta O, Tsuji Y, Kawano H et al. Indication for endoscopic resection of submucosal colorectal carcinoma: special reference to lymph node metastasis. Diagn. Ther. Endosc. 2000; 6; 101-109.

20. Ueno H, Mochizuki H, Hashiguchi Y et al. Risk factors for an adverse outcome in early invasive colorectal carcinoma. Gastroenterology 2004; 127; 385-394.

21. Pollheimer MJ, Kornprat P, Lindtner RA et al. Tumor necrosis is a new promising prognostic factor in colorectal cancer. Hum. Pathol. 2010; 41; 1749-1757. 
22. Jass JR, Morson BC. Reporting colorectal cancer. J. Clin. Pathol. 1987; 40; 1016-1023.

23. Bokkerink GM, de Graaf EJ, Punt CJ et al. The CARTS study: chemoradiation therapy for rectal cancer in the distal rectum followed by organ-sparing transanal endoscopic microsurgery. BMC Surg. 2011; 11; 34.

24. Bujko K, Richter P, Kolodziejczyk M et al. Preoperative radiotherapy and local excision of rectal cancer with immediate radical re-operation for poor responders. Radiother. Oncol. 2009; 92; 195-201.

25. Bedrosian I, Rodriguez-Bigas MA, Feig B et al. Predicting the node-negative mesorectum after preoperative chemoradiation for locally advanced rectal carcinoma. J. Gastrointest. Surg. 2004; 8; 56-62; discussion 62-63.

26. Guillem JG, Diaz-Gonzalez JA, Minsky BD et al. cT3NO rectal cancer: potential overtreatment with preoperative chemoradiotherapy is warranted. J. Clin. Oncol. 2008; 26; 368-373.

27. Berho M, Oviedo M, Stone $\mathrm{E}$ et al. The correlation between tumour regression grade and lymph node status after chemoradiation in rectal cancer. Colorectal Dis. 2009; 11; 254-258.

28. Kitajima K, Fujimori T, Fujii S et al. Correlations between lymph node metastasis and depth of submucosal invasion in submucosal invasive colorectal carcinoma: a Japanese collaborative study. J. Gastroenterol. 2004; 39; 534-543.
29. Burton S, Eddy B, Li WY et al. Reliability of pre-operative biopsies in the histological grading of colorectal adenocarcinomas. Ann. R. Coll. Surg. Engl. 2003; 85; 23-25.

30. Shia J, Guillem JG, Moore HG et al. Patterns of morphologic alteration in residual rectal carcinoma following preoperative chemoradiation and their association with long-term outcome. Am. J. Surg. Pathol. 2004; 28; 215-223.

31. Compton CC, Fielding LP, Burgart LJ et al. Prognostic factors in colorectal cancer. College of American Pathologists Consensus Statement 1999. Arch. Pathol. Lab. Med. 2000; 124; 979-994.

32. Amajoyi R, Lee Y, Recio PJ, Kondylis PD. Neoadjuvant therapy for rectal cancer decreases the number of lymph nodes harvested in operative specimens. Am. J. Surg. 2013; 205; 289 292; discussion 292.

33. Elferink MA, Siesling S, Lemmens VE et al. Variation in lymph node evaluation in rectal cancer: a Dutch nationwide population-based study. Ann. Surg. Oncol. 2011; 18; 386-395.

34. Lykke J, Jess P, Roikjaer O, Danish Colorectal Cancer Group. A minimum yield of twelve lymph nodes in rectal cancer remains valid in the era of neo-adjuvant treatment: results from a national cohort study. Int. J. Colorectal Dis. 2015; 30; 347-351.

35. Persiani R, Biondi A, Gambacorta MA et al. Prognostic implications of the lymph node count after neoadjuvant treatment for rectal cancer. Br. J. Surg. 2014; 101; 133-142. 